

\title{
Keeping pace with technology: Drones, Disturbance and Policy Deficiency
}

\begin{abstract}
This article analyses regulatory responses to rapid intensification of the use of drones/remotely piloted aircraft (RPA) in the context of wildlife protection. Benefits and disadvantages of the technology to wildlife are examined, before three key limitations in policy and law are identified: failure to address wildlife disturbance in RPA regulation; reliance upon insufficiently comprehensive existing wildlife protection legislation to manage disturbance effects; and limited species-specific research on disturbance. A New Zealand case study further reveals an inconsistent regulatory approach struggling to keep pace with innovation, inadequate regulatory capture of environmental effects due to exemption as "aircraft", and no recognition that specific geographical locations, such as coastal areas, distinguished by recreational pressures and high numbers of threatened species require special consideration. Recommendations include acknowledging the impact on wildlife in policy, gap analysis of legal arrangements for protection from disturbance (including airspace), and adoption of minimum approach distances to threatened species.
\end{abstract}

Keywords: UAV; RPA; drone; aircraft; regulation; wildlife conflict; wildlife disturbance

\section{Introduction}

Remotely Piloted Aircraft (RPA) have been embraced by government, industry and recreational users in a wide range of applications. To date, the regulatory response has been focussed on understanding the safety and privacy risks of RPAs to humans and their property, yet the application and rapid growth of this technology also raises a series of questions for environmental law and management.

This article addresses the phenomenon of wildlife disturbance by RPA and analyses responses of law and policy. Jasanoff $(1987,197)$ observed that regulation of emerging risks to the environment often involves the frontiers of current scientific knowledge where consensus among scientists is most fragile. Here, consideration at law 
is likely to be impeded by its nascent nature. For example, the lack of recognition of, and research into, the phenomenon of disturbance of wildlife species has been identified as an issue for environmental law and policy more generally (Wallace 2016; Dear et al. 2015; Weston et al. 2012) notwithstanding how RPA use may further affect speciesspecific disturbance and responses. The variety in both form and deployment of RPA and the varying stimuli produced are further complicating factors, and although research is emerging, a full understanding of or agreement upon any adverse impacts of the technology has yet to be established. RPA can occupy airspace and approach species in new and unique ways. Conservation and protection of aerial habitat is not well-recognised (Davy et al. 2017) and RPA present new challenges for law and policy.

In addition, competing tensions between enabling beneficial applications of the new technology and protecting threatened wildlife are evident, and sitting in the background is the matter of sufficiency of pre-existing threatened species law to fill any regulatory void arising through introduction of the new technology. Delivering adequate regulatory capture whilst catering for a wide range of potential users in diverse environments, with varying skills, purposes and knowledge, requires careful consideration. Furthermore, the issue of the scale of any regulation is relevant to regulatory capture. Here, the common characterisation at law of RPA as aircraft, and the central government scale at which these are usually regulated, may limit scope for managing environmental effects at the local level or in particularly vulnerable habitats.

The aim of this article is to address how the use of RPA may affect wildlife, and to analyse the purpose and fit of the law in response. We begin by reviewing the literature concerning RPA usage and assessing the benefits and drawbacks for wildlife. We follow by considering the phenomenon of wildlife disturbance and the established effects of drone technology in this regard. The enquiry then turns to regulation of observed effects, 
and examines recent regulatory efforts in the USA and Australia. To more closely consider regulatory effect we then use a case study and investigate how RPAs are regulated in New Zealand and to what extent the phenomenon of wildlife disturbance is understood and responded to in the regulatory arrangements. Drawing upon this data, we also make policy recommendations that will have resonance for all countries similarly aiming to balance the costs and benefits of the rapidly growing issue of RPA use.

By way of method, key legislation, associated rules, guidance material and commentary were analysed to understand relevant mechanisms for controlling RPA. For the New Zealand case study, an analysis of government agencies controlling public areas was carried out to examine the nature and extent of control imposed and identify any universal controls upon RPA use on public land in New Zealand. District and Regional Councils were identified as key targets, as these agencies are responsible for the management of open space, parks and reserves and for the control of effects of activities on the environment (Local Government Act 2002, Reserves Act 1977, Resource Management Act 1991). The Department of Conservation, the central government agency responsible for the management of the public conservation estate and for the protection of wildlife (Conservation Act 1987, Wildlife Act 1953 and Marine Mammals Protection Act 1978), was also included.

The method applied was a desktop study of the agency policies to identify presence or absence of a policy related to the conditions surrounding land owner consent and RPA operations, and an investigation of the details of the policy with specific reference to controlling impacts upon wildlife. The study comprised of 11 regional authorities and 66 territorial authorities (including five unitary authorities) and the Department of Conservation. It was conducted in March-April 2016. A website search was conducted as it represents an obvious point for a RPA operator's initial enquiry into 
RPA use, and local authorities are encouraged by the CAA to advertise their approach via websites (Civil Aviation Authority 2015, 2).

The data collection and subsequent analysis demonstrate a range of issues to be considered in delivering regulatory responses that make adequate provision for avoidance or mitigation of potential harm to threatened wildlife from the emergent technology. The discussion generated has universal features which resonate beyond the New Zealand context and require addressing in all countries where RPA use is similarly growing.

\section{The Pace and Impact of RPA Technology}

RPA, also known as drones, unmanned aerial vehicles or systems (UAV, UAS) are a broad category of small electronically controlled aerial vehicle. Advancement of drone technology was predominantly driven by military requirements and over the past decade the rapid development of high speed auto-stabilising microcontrollers and battery technology has led to smaller, more affordable RPA that has considerably expanded the market uptake to include the general public (e.g., Linchant et al. 2015, Jones et al. 2006). Hardware advancement and economies of production scale, in areas such as the recreational first person view immersive flying experience, drone racing, and aerial photography/video has also driven uptake. The development of inexpensive open-source autopilot hardware and flight-planning software now makes GPS-based computer-driven flight operations accessible to most commercial, research and civilian operators (Arifianto and Farhood 2015; Dryanovski et al. 2013; Meier et al. 2012; Scherer et al. 2012).

RPA technology can be partitioned broadly into military, recreational and commercial types with research and humanitarian purposes falling loosely within the latter. Further distinction is based on form, function and take-off mass. This article 
focuses on the commercial and recreational drone context, although there are issues in common and overlap in technology across applications (Boucher 2015; Zolderdo et al. 2015; Sandvik and Lohne 2014; Tirian 2014). The broad range of RPAs includes a variety of forms and sizes from micro-scale (Capello et al. 2012) to the large military unmanned drone planes (Springer 2013), and can include kites, blimps and balloons dependent upon their imaging payload (Klemas 2015). RPA have been classified according to characteristics such as size, weight and function (Hoffer et al. 2014; Anderson and Gaston 2013; Limnaios et al. 2012; Watts et al. 2012). Most RPA, however, fit into two basic functional categories: either fixed wing planes, that need to sustain velocity in order to stay airborne, or rotor propelled vehicles (rotating wings) which fly or hover with fine control of rotor speed using a flight controller. Each has its functional advantages in the trade-off between weight, speed, control, flight longevity and stability.

In contemplating the breadth of RPA technology it is important to note that flying is only one part of a broader survey platformprocess. RPA operation also includes the $\underline{\text { flight control system, radio linkage,--payload, navigation control, hazard and equipment }}$ management, communications and flight planning. So any potential risk to wildlife or habitat is related to the quality and functionality of all components, as well as the skill and preparedness of operators. Operator class and purpose also have bearing, as some operators (e.g. research and conservation users) are subject to additional institutional procedures and the assessment of impact to species.

RPA have been used for a range of applications in scientific and commercial industries (Thompson and Saulnier 2015). Benefits include their affordability, versatility, transportability, and ease of use in contrast to survey by piloted aircraft (Colomina and Molina 2014). 
Particular benefits accrue in wildlife management and conservation. It is therefore important that any potential risks of RPA to wildlife, and the need for associated control are assessed in view of these gains. RPA enable new forms of survey functionality (Table 1). For example, with regard to wildlife management small, agile, remotely piloted RPA which achieve close proximity to the ground or object of interest are adding important capability to observational methods, and providing useful ecological data and research efficiencies (Evans et al. 2015; Sandbrook 2015; Weissensteiner et al. 2015; Whitehead et al. 2014; Koh and Wich 2012). Absence of a human pilot and the lightweight miniaturised form of the RPA allow flight operations into environments which are otherwise difficult, dangerous or inaccessible.

Table 1. Research demonstrating RPA benefits.

\begin{tabular}{|c|c|c|}
\hline $\begin{array}{l}\text { Distinctive RPA } \\
\text { characteristic }\end{array}$ & Resulting capability & Illustrating example \\
\hline $\begin{array}{l}\text { Access to views that } \\
\text { are below the lowest } \\
\text { allowable flying } \\
\text { height for piloted } \\
\text { aircraft, but above the } \\
\text { reach of observers or } \\
\text { structures at ground } \\
\text { level }\end{array}$ & $\begin{array}{l}\text { Enables very high resolution } \\
\text { and/or spatially accurate } \\
\text { imagery / point clouds } \\
\text { Enables close inspection of } \\
\text { sensitive / delicate / } \\
\text { inaccessible sites }\end{array}$ & $\begin{array}{l}\text { Leon et al. 2015; Siebert } \\
\text { and Teizer } 2014 \\
\text { Lehmann et al. 2016; Nishar } \\
\text { et al. 2016; Weissensteiner } \\
\text { et al. 2015; Dulava et al. } \\
\text { 2015; Evans et al. 2015; } \\
\text { Ramsey et al. } 2014\end{array}$ \\
\hline $\begin{array}{l}\text { Computer controlled } \\
\text { GPS-referenced flight } \\
\text { controller }\end{array}$ & $\begin{array}{l}\text { Enables precise and / or } \\
\text { repeatable flight path }\end{array}$ & $\begin{array}{l}\text { Brouwer et al. 2015; Chabot } \\
\text { et al. 2015; Evans et al. } \\
\text { 2015; Turner et al. 2015; } \\
\text { Vas et al. 2015; Wing et al. } \\
\text { 2013; Rodriguez et al. } 2012\end{array}$ \\
\hline $\begin{array}{l}\text { Small, agile with } \\
\text { precise course } \\
\text { placement }\end{array}$ & $\begin{array}{l}\text { Enables 3D detail or view } \\
\text { that is inaccessible from } \\
\text { ground or piloted aircraft } \\
\text { Greater manoeuvrability / } \\
\text { agility for more specific flight } \\
\text { control; flight between/ } \\
\text { within structures }\end{array}$ & $\begin{array}{l}\text { Ramsey et al. 2014; Siebert } \\
\text { and Teizer 2014; Vasuki et } \\
\text { al. } 2014 \\
\text { Weissensteiner et al. 2015; } \\
\text { Chisholm et al. } 2013\end{array}$ \\
\hline $\begin{array}{l}\text { Vertical take-off / } \\
\text { landing / hovering. }\end{array}$ & Hover / positional hold & $\begin{array}{l}\text { Weissensteiner et al. 2015; } \\
\text { Durban et al. 2015; Ramsey } \\
\text { et al. } 2014 .\end{array}$ \\
\hline
\end{tabular}




\begin{tabular}{|l|l|l|}
\hline & $\begin{array}{l}\text { Enables collection or } \\
\text { deploying of samples/objects }\end{array}$ & $\begin{array}{l}\text { Brady et al. 2016; } \\
\text { Detweiler et al. 2015 }\end{array}$ \\
\hline $\begin{array}{l}\text { Can operate without } \\
\text { human occupant }\end{array}$ & $\begin{array}{l}\text { Enables to higher risk flying } \\
\text { environments than by piloted } \\
\text { vehicles, or in-situ } \\
\text { observations }\end{array}$ & $\begin{array}{l}\text { Evans et al. 2015; Lucieer } \\
\text { et al. 2014; Mulero- } \\
\text { Pázmány et al. 2014; } \\
\text { Merino et al. 2012; } \\
\text { Ambrosia et al. 2011 }\end{array}$ \\
\hline $\begin{array}{l}\text { Hardware is mobile } \\
\text { and portable }\end{array}$ & $\begin{array}{l}\text { Enables survey gear-set to be } \\
\text { deployed from remote or } \\
\text { difficult location }\end{array}$ & Chabot et al. 2014 \\
\hline $\begin{array}{l}\text { Simple low-cost } \\
\text { deployment }\end{array}$ & $\begin{array}{l}\text { Enables small-scale, ad hoc } \\
\text { or frequently visited surveys } \\
\text { at relatively low deployment } \\
\text { costs }\end{array}$ & $\begin{array}{l}\text { Brouwer et al. 2015; } \\
\text { Weissensteiner et al. 2015 }\end{array}$ \\
\hline
\end{tabular}

Yet while delivering added capacity for a wide range of research applications and users, the same favourable characteristics, particularly manoeuvrability and proximity, produce the potential to disturb wildlife where not adequately managed. RPA can inhabitoccupy space not previously accessed by humans or machines, and in this way present a new and unique challenge for managing disturbance effects. This balance between the costs and benefits to wildlife presents a conundrum for environmental law and policy.

RPA use is growing fast. The full extent of current use is difficult to quantify, and prediction of future trends lack data, but a recent meta-analysis of the RPA market (Canis 2015) indicates a consumer market in its infancy with exponential growth in drone production and research investment predicted. The cumulative industry worth has been valued at US\$91 billion, with significant investment in commercial RPAs indicating major growth ahead (Peasgood and Valentin 2015).

Beyond the burgeoning commercial uptake, the potential for ubiquitous presence of RPA in the environment is heightened by the quick uptake by recreational users. These trends argue that we should expect an increasing likelihood of encounters between wildlife and RPA, thus increasing potential for conflict where operations are 
insufficiently controlled. The variety of users combined with the relatively unique capacity of RPA to approach wildlife from above terrestrial, aquatic and marine habitat suggests a challenging regulatory context with increased potential for encounters.

\subsection{Drones and Disturbance}

Whilst recognising the benefits of RPA use to wildlife and conservation, an emerging awareness of negative impacts as a consequence of RPA and wildlife interaction indicates a need to condition its use.

Disturbance of wildlife species is a phenomenon occasioned by a variety of circumstances. Broadly defined it encompasses the behavioural or physiological response of animals to the presence of stimuli, such as a potential predator or anthropogenic causes such as humans or vehicles (Weston et al. 2012, 269; Glover et al. 2011, 327; Fox and Madsen 1997; Van Der Zande and Verstrael 1985, 90). In the context of bird species, the adverse impacts that may arise include changes in distribution (e.g. short term movement or displacement), behaviour (e.g. flight response or increased vigilance), demography (e.g. reduced fecundity/survival) and changes in population size (Gill 2007, 10).

Disturbance effects have been related to a wide range of activity extending from the simple approach of a human or animal, to the use of vehicles, boats, aeroplanes and other machinery (Weston, Schlacher and Lynn 2014; Weston et al. 2012; Tarr, Simons and Pollock 2010; Lord et al. 2001). Researchers have also begun to link disturbance to RPA use. For example, potential for mortality and injury through collision, and disturbance of wildlife species are highlighted as an issue (Hodgson and Koh 2016; Rümmler et al. 2015; Ditmer et al. 2015; Lambertucci, Shepard and Wilson 2015; Stanley et al. 2015; Vas et al. 2015). 
This developing issue is of concern, particularly in geographical locations such as New Zealand coastal areas, where disturbance pressures are already on the rise (Woodley 2012, 233; Lord et al. 2001, 237), and which are distinguished by high numbers of threatened species (Hitchmough 2013). In calculating disturbance effects and guidance, jurisprudence suggests that the rarity or conservation status of a species correlates to a lower threshold of harm when describing or constituting a disturbance effect (Wallace 2016, Vivienne Morge v Hampshire County Council [2011] UKSC 2). Accordingly, it is important to identify, contextualise and quantify a disturbance effect in order to determine an associated regulatory response.

Although disturbance is established as a key stress, evidence is lacking as to when, and at what levels, it becomes adverse (Guay et al. 2016; Møller et al. 2014). In addition, the more general problem exists that making a link to a bird's behavioural or physiological response and an impact at population level is not well researched, while establishing and managing disturbance is made more complex by the species-specific nature of a stress response (Navedo and Herrera 2012, 373; Glover et al. 2011 326; Liley and Sutherland 2007, 82; Blumstein et al. 2003, 99). Despite its lesser stature amongst other pressing concerns, such as habitat loss, ecosystem degradation and predation, it has been argued that reducing disturbance to species may be a fundamental measure to compensate for stresses caused by potentially more intractable pressures such as climate change (Zuberogoitia et al. 2014, 416; Mawdsley et al. 2009, 180).

While some commentary (e.g. Gonzalez et al. 2016, Hodgson et al. 2013) suggests that RPA use in conservation management may reduce disturbance effects to species by preventing a more intrusive human approach, other commentary argues that RPA interactions can have adverse disturbance impacts including those described in relation to Adelie penguin (Rümmler et al. 2015), black bears (Ditmer et al. 2015), and seagulls 
and raptors (Lambertucci, Shepard and Wilson 2015). The potential for disturbance is attributed to the low altitude presence, noise and prevalence of RPA. Similarly, disturbance may be a factor in any mass use such as the simultaneous deployment of fleets of 'swarming' drones that are being trialled in forest fire surveillance (Stanley et al. 2015, Merino et al. 2012).

Evidence also suggests that equipment choice and operational protocols can significantly influence any impact. Vas et al. (2015) recommend adjusting angle of approach and altering approaching distance according to species. Hodgson and Koh (2016) support the adoption of the precautionary principle in lieu of evidence and point to the need for a code of best practice to alleviate risk to wildlife through RPA operation. The research conducted by McEvoy et al. (2016) highlights the variation in RPA effects and the importance of management control in realising the potential of the technology to provide benefits for wildlife. Similarly, in a study which investigated how RPA sound variously affects five target species, Scobie and Hugenholtz (2016) identified flight altitude as a critical factor in avoiding behavioural responses by the target species.

These recommendations were made in the context of use by wildlife researchers, and whilst this is clearly an area where RPA are likely to approach wildlife, it is the rapidly rising high numbers of commercial and hobbyist users which most significantly intensify the potential for disturbance in the environment. Many of these users can also be distinguished from wildlife managers due to lower levels of awareness of wildlife presence in the environment and associated sensitivities.

The rise of RPA technology and its potential for widespread commercial and recreational use adds impetus to the need for further research in relation to balancing the benefits with potential disturbance effects. In addition, it suggests the need for policy guidance and regulation of adverse disturbance effects particularly for threatened species, 
to which a lower threshold of harm from disturbance may be applied. The balance of the article now considers to what extent RPA policy and regulation is effective in this regard.

\section{Regulation of RPA and consideration of wildlife disturbance}

The research outlined so far conveys a sense of policy and the law playing catch-up to the rapid adoption of the technology, and that in many instances regulatory effort is uneven (e.g. Perrit and Plawinski 2015; Butler 2014; Clarke and Moses 2014). It also highlights that while circumstances exist where regulation is necessary, the risks associated with RPA use need to be carefully assessed and quantified to ensure that any regulation is well targeted, and does not unnecessarily limit the benefits from RPA applications (Giboney 2015, 181; Perrit and Plawinski 2015, 389; Freeman and Freeland 2014).

With regard to public safety, an area that has received some policy attention, Clarke and Moses $(2014,267)$ identified the need to establish "regulatory connection" when considering the fit of an existing regulatory system with new forms of conduct such as drone flight. The authors recognise the potential for the development of a regulatory void, or alternatively a lack of fitness for purpose whereby existing laws require reconnection to the new technological landscape. Vas et al. $(2015,1)$ similarly note that although air traffic regulations in certain states strictly control the civil use of drones, no ethical guidelines exist with respect to their potential impacts on animal welfare. In short, although the potential for wildlife mortality/injury through collision, aerial habitat disruption and disturbance are recognised (Lambertucci, Shepard and Wilson 2015), regulation of RPA use as a consequence of potential harm to wildlife does not feature as a key concern. To explore this point further we now turn to an overview of how drones are regulated in the USA and Australia, before examining New Zealand law and policy in more depth. 


\subsection{USA and Australia}

Recent regulatory change in both the USA and Australia demonstrate moves to free up the burgeoning recreational use of small RPA and to reduce red tape on commercial applications, particularly in Australia, in the instance of commercial operations upon private land. In August 2016 the USA Federal Aviation Administration (FAA) amended its regulations (14 CFR Parts 21, 43, 61, et al. Operation and Certification of Small Unmanned Aircraft Systems; Final Rule) to allow the operation of small unmanned aircraft systems in the National Airspace System. As a consequence, where Unmanned Aircraft Systems are flown "for fun" and weigh below $25 \mathrm{~kg}$, no pilot licensing requirements apply, although operators must comply with simple operation rules including registration, right of ways, line of sight limitations, community guidelines and airport controls (Part 107, subpart B-Operating Rules).

The impact of RPA upon wildlife is not addressed by the rules, a position ostensibly affected by the intention to enable recreational use of small RPA, recognition of the benefits of RPA to wildlife management (and wider societal benefits) and the requirement of all drone operators to comply with pre-existing threatened species law concerning both hazard from loss of control and wildlife disturbance. In relation to the latter, the commentary to the newly introduced rule stated (Federal Register / Vol. 81, No. 124 / Tuesday, June 28, 2016 / Rules and Regulations, 42188):

In response to commenters who expressed concerns about negative impacts to birds and other wildlife, the FAA emphasizes that this rule does not authorize the harassment, harming, or killing of birds, mammals, or ocean dwelling animals. These types of actions are prohibited by other laws and regulations such as the Migratory Bird Treaty Act (see 16 U.S.C. 703; 50 CFR part 21), the Endangered 
Species Act (ESA), and the Marine Mammal Protection Act (MMPA). The FAA emphasizes that in addition to satisfying the provisions of this rule, remote pilots of a small UAS will remain subject to all applicable laws, including environmental and wildlife laws.

An issue raised by submitters concerning this position was the likelihood of RPA operators being familiar with the requirements of the law, and submissions by the National Oceanic and Atmospheric Administration (NOAA) and the Ventura Audubon Society suggested testing operator knowledge of operating in the context of wildlife and an applicant's understanding of Federal and State wildlife protection laws (Federal Register / Vol. 81, No. 124 / Tuesday, June 28, 2016 / Rules and Regulations, 42168). The position taken by the FAA in response was again essentially that operators are required to comply with the law, although in relation to potential risks to marine mammals the commentary noted that "the FAA strongly recommends that remote pilots conducting operations near marine wildlife familiarize themselves with NOAA regulations and guidance" (Federal Register / Vol. 81, No. 124 / Tuesday, June 28, 2016 / Rules and Regulations, 42189).

The commentary clearly recognises the potential for harm, but regulators defer to the expertise of other agencies in this regard and to dedicated wildlife protection laws and regulations. What this approach does not clearly address is the adequacy of existing legislation to respond to any new threat. A particular matter of concern for this article is the ability of existing law and policy to protect threatened species from potential cumulative disturbance effects stemming from permitting widespread recreational use of RPAs on both public and private land inhabited by threatened species. 
Other public agencies tasked with conserving threatened species have similarly acknowledged the potential for harm. For example, in the United States the government has moved to ban drones from National Parks due to concerns of wildlife harassment, and the impact of noise upon visitors (Bolos, 2015 416) and more recently the Government of South Australia has moved to ban RPA without a permit from operating in national parks under the new National Parks and Wildlife Regulations (National Parks) 2016. National parks operate with combined conservation, recreation and tourism mandates, which at times conflict. Regulating RPA through permits in national parks enables scrutiny of operations to ensure a balanced approach to securing compliance with mandates, and may enable exemptions for beneficial applications.

Restrictions in national parks manage the problem within the bounds of protective areas. However, the benefit of the approach is limited by the spatial constraints of the reserves, to the disadvantage of species which exist in unprotected areas or mobile species which move between the environments. Where both RPA and threatened species are pervasive in the environment, then more sustained protection is obtained through species protection as opposed to discrete habitat protection, a point that will be returned to in the conclusion. This is particularly so for threatened wildlife which is thinly and widely distributed in areas frequented by the public, such as is common with threatened shorebirds in coastal New Zealand and Australia.

In a manner similar to the USA, Australia has also reduced regulatory constraints in relation to RPA operation. From 29 September 2016 the Civil Aviation Safety Regulations Part 101 enable those "flying for fun" an RPA weighing less than 2 kilograms to fly without needing to be certified providing simple operational safety rules are followed (Rule 101.238 Meaning of standard RPA operating conditions). Impact to wildlife is not listed as an operational constraint. Similarly, commercial users flying RPA 
weighing less than $2 \mathrm{~kg}$ do not require an RPA operator's certificate, subject to giving notification of operation to the relevant authority. RPA operations excluded from the licensing requirements are also extended by the Rules to other instances, including where over land owned or occupied by the owner of the RPA for purposes such as agricultural operations, and the carriage of cargo (Rule 101.237 Meaning of excluded RPA).

The permissive approach to RPA, (particularly towards recreational users in the under $2 \mathrm{~kg}$ weight category) signals either a lack of administrative concern for potential impacts to wildlife, or confidence that such impacts will not arise, or if they do, that risk of harm will be satisfactorily managed by pre-existing legislation.

Whilst acknowledging the benefits for wildlife from RPA technology, we consider that enthusiasm for the adoption of a permissive regulatory approach may require tempering in specific contexts due to several key reasons. The first is that the risk of RPA to wildlife is unclear and likely to be affected by the significant variability seen in RPA construction, form and associated behavioural characteristics, and also their deployment, operator skill, and the ramifications of this in relation to noise, vibration and presence. Secondly, the disturbance literature suggests that disturbance effects are species-specific and subject to variability. In addition, the significance of a disturbance effect is also uneven, as more threatened species may have a higher risk of harm. Where protective legislative provision turns upon proof of a 'significant' impact, calculation of species rarity must be weighed.

A further confounding factor is the inability of such policy to capture accumulating impacts of many minor disturbance effects, which may as a group constitute a significant effect. Where a country has comprehensive rules in place preventing harassment or disturbance of wildlife irrespective of source, concern may not arise in respect of a regulatory void, as the pre-existing law will cover the gap no matter the 
source. However, careful consideration needs to be given as to what constitutes comprehensive protection where the risk of harm is being enabled in a pervasive manner throughout the environment.

So questions arise as to whether a permissive system can function adequately if there is effective pre-existing species legislation, operator training, or extant animal ethics permissions. The following discussion of the New Zealand position considers these matters in context and develops the discussion of RPA use and regulation more deeply. We examine the fit and purpose of the law, and identify key gaps in terms of comprehensive regulation. We demonstrate the ways in which both existing law and policy, and recently introduced RPA-specific regulation may be deficient in anticipating wildlife disturbance effects and providing mechanisms and policy guidance for managing potential environmental effects generated by RPA operation. The discussion underscores the need for mechanisms that address disturbance of wildlife species in a practical manner across all media including airspace.

\section{New Zealand Law and Policy}

\section{Civil Aviation Rules and application}

The clear treatment of RPA as aircraft sets the frame for the New Zealand approach. Aircraft, defined widely to include Remote Piloted Aircraft Systems (s 2), are regulated under the Civil Aviation Act 1990 and Civil Aviation Rules 2015 Parts 101 and 102.

- In shaping the regulatory approach, the rules elect aircraft weight as a determining characteristic and divide RPA into two broad categories based on the threshold weight of $25 \mathrm{~kg}$. Most RPA in New Zealand currently fall within the scope of Part 101 for which no operator certification is required. 
In focusing upon the weight of the RPA, the rules make no apparent distinction between the nature of use, for example commercial/recreational or government/private. Classification by weight may also limit consideration of other variables, such as level of risk/hazard associated with flying height, velocity, and take-off weight compared to maximum thrust and rotor velocity (which influence stability and noise), each of which may be differently correlated to risk of damage to person and property or to disturbance of wildlife. Instead, Part 101 imposes a series of general constraints upon all RPA use in the $25 \mathrm{~kg}$ category and below, which if complied with mean that no further authorisation is required for operation. The key constraints contained within the rules are directed towards minimising hazards to persons, property and other aircraft (Rules 101.7$11,101.13,101.209,101.211,101.207(a)(3))$. Protection of personal privacy and property rights is afforded through requirement for consent to fly above any person and consent from the property owner or occupier to fly above property (Rules 101.207(a)(1) (i-ii)).

The issue of wildlife disturbance, or indeed any other impact upon the non-human environment, is not specifically contemplated by the Rules. The lack of specificity regarding treatment of wildlife in the Rules creates a gap in the regulation, which is accompanied by an absence of policy guidance concerning the environmental impacts of RPA operation. As a consequence, the requirement for property owner consent becomes the default position for limiting or conditioning RPA operations under Part 101. Significantly, this typically places the control and conditioning of operations generating local level effects in the hands of property owners. This is of concern in the New Zealand environment where levels of threatened endemic species are elevated in contrast with global averages (IUCN 2015) and significant numbers of threatened species inhabit areas on private land (Ministry for the Environment 2007, 3, 6). 
To assess the extent to which environmental controls may be imposed through the requirement for land owner consent we analysed local authority and Department of Conservation guidance to understand how they manage RPA use on their property.

The agency guidance material identified was examined to determine their approach. Of Formatted: Indent: First line: $0 \mathrm{~cm}$ 66 territorial authorities (including 5 unitary authorities), 29 had no policy guidance and 37 had some RPA guidelines. Of these, only five specified rules or criteria relating to proximity to wildlife or habitats (Table 2). Similarly, of 16 regional authorities, ten had no guidance and six had some guidance, with only two relating in some way to wildlife.

As highlighted in the literature review, most of the policy context and justification provided was directed to matters of privacy, nuisance and safety of person and property. Wildlife related consent conditions were limited to brief cautions about flight distance approaches (typically limited at $20 \mathrm{~m}$, and $50 \mathrm{~m}$ in one case) or flight over habitat. Furthermore, no consideration or guidance was given concerning locations of high wildlife density except for passing reference to discrete bird species, and the example of two Regional authorities respectively providing conditions against flying within $50 \mathrm{~m}$ of wetlands, or $20 \mathrm{~m}$ from coastal and river margins.

Table 2. Summary of RPA guidance, conditions or allowances.

\begin{tabular}{l|ccc}
$\begin{array}{l}\text { Authority type } \\
\text { Condition category }\end{array}$ & $\begin{array}{l}\text { Territorial } \\
\text { authority }\end{array}$ & $\begin{array}{l}\text { Regional } \\
\text { authority }\end{array}$ & $\begin{array}{l}\text { Dept. of } \\
\text { Conservation }\end{array}$ \\
\hline $\begin{array}{l}\text { Number with no guidance* } \\
\text { Number with guidance }\end{array}$ & 29 & 10 & 0 \\
- RPA generally prohibited & 11 & 6 & 1 \\
- RPA prohibited w allowances & 5 & 1 & 1 \\
- RPA generally permitted & 21 & 4 & 0 \\
- CAA rules only* & 0 & 1 & 0 \\
Guidance to protect & & & 0 \\
biodiversity values stated & 8 & 2 & 1 \\
\hline Num of regions/districts & 66 & 16 & 1
\end{tabular}




\section{Wildlife Protection Law and Policy}

Protection of wildlife from RPA impacts is further confounded by limitations attaching to the legislation in New Zealand which governs both the protection of wildlife (Wildlife Act 1953) and resource use, development and protection (Resource Management Act 1991(RMA)). The Wildlife Act 1953 is deficient in that it does not enable general protection of wildlife from disturbance that is independent of "hunting and killing". The scope of disturbance has been read down by judicial interpretation to not include unintentional disturbance, such as when wildlife is startled without a person taking direct action in relation to it. As a consequence, wildlife in New Zealand is not well protected from incidental disturbance (Wallace 2016). An exception arises in terms of protection gained by marine mammals (Marine Mammals Protection Act 1978, and Marine Mammals Protection Regulations 1992 (SR 1992/322)), which enable protection from disturbance by aircraft through the regulation of vehicle approach distances.

A final legislative deficiency in New Zealand is the exemption of aircraft from regulation under the RMA which limits control over overflying aircraft to prescribed noise emission controls for airports (s 9(5) and s 12(5)). The rationale for this exclusion includes the lack of connection between overflying aircraft and the land and the lack of control a land owner or occupier may have over the random and momentary intrusion of an aircraft into his or her air space (Dome Valley District Residents Soc Inc v Rodney District Council [2008] 3 NZLR 821 at [40-43]). However, in this regard RPA operation can be distinguished from archetypal aircraft overflight due to the close spatial connection of RPA to land and operator, and the ability of common RPA (such as quadcopters) to 
orientate vertically and horizontally and to hover, pitch, roll, and yaw in close proximity to a subject.

As a result of the RMA exemption for aircraft, disturbance effects of RPA to wildlife are not captured in the same way that other effects of activities on the environment would be. Consequently, tools such as resource management plans enabling protective zoning, setbacks and buffers for habitat and species are not available. Furthermore, important protective policy, such as the New Zealand Coastal Policy Statement 2010, which applies the precautionary principle and requires avoidance of effects on threatened indigenous species loses traction in the face of RPA operations. Exclusion as aircraft under the RMA, compounds with a lack of a legal response to disturbance impacts that arise incidentally to other activities under the Wildlife Act 1953, to create a double strikeout under the two main statutes with functions to protect wildlife. These deficiencies are deepened by the inability to scrutinise the level of potential effect created by different classes of RPA within the under $25 \mathrm{~kg}$ category.

The results of the case study reveal the patchy and inconsistent approach to the control of potential impacts to wildlife from RPA use. The most significant regulatory gap arises in relation to protection of wildlife on private land and in the common marine and coastal area. Without requirement from the landowner, disturbance effects arising incidentally to an RPA operation on private land or in the coastal area may go unchecked. This is of particular concern in New Zealand as significant amounts of rare and threatened biodiversity inhabit these areas. We argue that for the protection of wildlife, this level of control is inappropriate and likely to result in a lack of comprehensive and consistent treatment at law.

The position improves somewhat on public conservation land with requirement for an application for concession from the Department of Conservation in relation to all 
activities on public conservation land. Similarly, local authorities exercising control over open space areas and Council owned property may adopt practice of scrutiny, although it can be seen from the results above that approaches are far from rigorous or uniform as concerns any form of wildlife protection.

The examination suggests that the RPA control is focused upon damage to person and property and that scant consideration is given to impacts upon wildlife. Eight of the authority examples referred to avoiding wildlife, but without reference to disturbance. There was no wildlife reference made in conjunction with policy advice creating operational constraints beyond awareness. In five cases, $20 \mathrm{~m}$ distance was noted as the closest permissible approach of RPA to species or habitat, and in one case a $50 \mathrm{~m}$ limit was described.

The evidence base supporting these requirements is unclear, but they are significantly less than the $100 \mathrm{~m}$ distance limitation recommended by Vas et al. (2015, 14) and insufficiently defined to comprehensively respond to either variation in RPA type and between species. No species-specific guidance was evident to explain vulnerability of species to disturbance with particular species or in reference to sensitive life-cycle stages. It is evident that the regulatory code introduced to control RPA operations in New Zealand does not provide threatened species in New Zealand with consistent protection from RPA operations.

At the same time, any safety net to cushion species from RPA disturbance cannot be found in existing legislation as a result of significant gaps in protection from disturbance and application of law to RPA. In this rapidly developing area, policy has clearly struggled to keep pace with technology. We can now better appreciate how the nuances of RPA use, from the weight, to the operators, to their purpose, are not well 
considered in existing legislation, which is more designed for public protection than wildlife disturbance.

\section{Discussion and Conclusion}

RPA use is growing fast and there is a paucity of research into the extent to which law and policy provide an effective response. We have demonstrated the benefits of RPA to wildlife, but also the ways by which unmanaged RPA use may cause disturbance effects to wildlife through low altitude presence, noise and prevalence. Further, that these effects may vary dependent upon the RPA, the species in question and the skills of the operator. We also argue how in quantifying disturbance effects, consideration must be given to the conservation status of species, as a lower threshold of harm may be required. In response to this problem we make four key policy recommendations.

First, in order to respond to the potential for disturbance effects we recommend that RPA operations be guided by specific policy addressing impacts to wildlife and where necessary regulated to prevent harm from disturbance. Further research may be required to inform such policy and relate it to differing national and species circumstances. We recommend that the policy be available on civil aviation websites, or at least a clear direction to alert RPA operators to the policy and its whereabouts.

Secondly, we advocate for research into regulatory measures requiring, where appropriate, distance setbacks of RPA operations from threatened and at risk species, in a manner similar to those applied in the protection of marine mammals from approaching people, animals, vehicles and aircraft. The rationale for this recommendation is that enabling species protection through setbacks will provide more comprehensive protection for endangered species in contrast to traditional forms of area protection, and species protection from disturbance reliant upon proof of intention and significance of impact. In addition, it will provide a clear indication to recreational operators as to expectations 
concerning operations in the presence of wildlife. In shaping regulatory approaches dispensation could be provided for wildlife researchers or other commercial operators compliant with codes of practice developed in a manner similar to that put forward by Hodgson and Koh (2016).

Thirdly, we recommend the inclusion of RPA within existing regulatory arrangements for protection of biodiversity, to ensure that where necessary threatened species receive adequate protection. The New Zealand example reveals shortfalls in the arrangements of the law concerning RPA control and impacts to wildlife. In particular, we argue that resting control by default in the hands of property owners prevents comprehensive scrutiny and control of potential impacts. The case study revealed how protection for threatened species from RPA operations will not be assured by passing responsibility to provide land owners who may be ill-equipped to monitor and manage this issue. This position is heightened by the burgeoning class of recreational RPA users. In order to achieve consistency, we suggest that for the purposes of environmental effects that RPA should not be excluded from regulatory capture by virtue of status as aircraft as is the case in New Zealand. Small hand-operated RPA flown by burgeoning groups of hobbyists in backyards, on farms and on beaches are different in nature and effect from larger more commercial aircraft activities. Although treatment as aircraft will continue to be necessary as it concerns aviation safety, effective scrutiny of local level effects, including those to wildlife is required. This recommendation is not intended to prevent a permissive approach where appropriate, rather by inclusion in existing resource management schemes, to enable flexible protection in particular areas and for sensitive species where appropriate.

Fourthly, we recommend that where countries elect to rely upon existing threatened species legislation/protective schemes to protect species from the impacts of 
RPA that they perform a gap analysis to ensure that the legislation adequately provides for disturbance effects to threatened wildlife across all media, including air. In particular, we recommend that threat status be included when assessing the significance of impact to species, and that measures adequately respond to cumulative effects of the sustained presence of RPA operations in an environment. The New Zealand example also highlights the particular vulnerabilities of discrete environments such as narrow coastal margins inhabited by threatened species where recreational pressures are intense.

Congestion of space is a condition of the Anthropocene and the forecasted exponential growth of RPA in the environment indicates further contestation for space both in the air and on the ground. The measures we recommend are intended to better provide protected spaces whereby adverse congestion effects are avoided and/or reduced to a level consistent with favourable conservation status for species.

\section{Acknowledgements}

We thank the anonymous reviewers for their helpful comments.

\section{Bibliography}

Ambrosia, V. G., S. Wegener, T. Zajkowski, D. V. Sullivan, S. Buechel, F. Enomoto, B. Lobitz, S. Johan, J. Brass, and E. Hinkley. 2011. "The Ikhana unmanned airborne system (UAS) western states fire imaging missions: from concept to reality (20062010)." Review of. Geocarto International 26 (2):85-101. doi: 10.1080/10106049.2010.539302.

Anderson, K., and K. J. Gaston. 2013. "Lightweight Unmanned Aerial Vehicles will Revolutionize Spatial Ecology." Frontiers in Ecology and the Environment 11 (3):138146. doi: 10.1890/120150. 
Arifianto, O., and M. Farhood. 2015. "Development and Modeling of a Low-Cost Unmanned Aerial Vehicle Research Platform." Journal of Intelligent \& Robotic Systems 80 (1):139-164. doi: 10.1007/s10846-014-0145-3.

Blumstein, D. T., L. L. Anthony, R. Harcourt, and G. Ross. 2003. "Testing a key Assumption of Wildlife Buffer Zones: Is Flight Initiation Distance a Species-Specific Trait?" Biological Conservation 110 (1):97-100. doi: http://dx.doi.org/10.1016/S00063207(02)00180-5.

Bolos, M. 2015. "A Highway in the Sky: A look at Land use Issues that will arise with the Integration of Drone Technology." U. Ill. JL Tech. \& Pol'y 2015:411-461.

Boucher, P. 2015. "Domesticating the Drone: The Demilitarisation of Unmanned Aircraft for Civil Markets." Science and Engineering Ethics 21 (6):1393-1412. doi: 10.1007/s11948-014-9603-3.

Brady, J. M., M. D. Stokes, J. Bonnardel, and T. H. Bertram. 2016. "Characterization of a Quadrotor Unmanned Aircraft System for Aerosol-Particle-Concentration Measurements." Review of. Environmental science \& technology 50 (3):1376-83.

Brouwer, R. L., M. A. De Schipper, P. F. Rynne, F. J. Graham, Ad J.H.M. Reniers, and J. H. Macmahan. 2015. "Surfzone Monitoring Using Rotary Wing Unmanned Aerial Vehicles." Review of. Journal of Atmospheric and Oceanic Technology 32 (4):855.

Butler, D. 2014. "The Dawn of the Age of the Drones: An Australian Privacy Law Perspective." UNSWLJ 37:434.

Canis, B. 2015. Unmanned Aircraft Systems (UAS): Commercial Outlook for a New Industry. In Congressional Research Service Publication 7-5700.

Capello, E., G. Guglieri, P. Marguerettaz, and F. Quagliotti. 2012. "Preliminary Assessment of Flying and Handling Qualities for Mini-UAVs." Journal of Intelligent \& Robotic Systems 65 (1):43-61. doi: 10.1007/s10846-011-9565-5. 
Chabot, D., \& Bird, D. M. (2015). Wildlife research and management methods in the $21 \mathrm{st}$ century: Where do unmanned aircraft fit in? 1. Journal of Unmanned Vehicle Systems, 3(4), 137-155.

Chabot, D., Carignan, V., \& Bird, D. M. (2014). Measuring Habitat Quality for Least Bitterns in a Created Wetland with Use of a Small Unmanned Aircraft. Wetlands, 34(3), 527533.

Chabot, D., Craik, S. R., \& Bird, D. M. (2015). Population Census of a Large Common Tern Colony with a Small Unmanned Aircraft: e0122588. PLoS One U6 10(4).

Chisholm, R.A., J. Cui, S.K.Y. Lum, and B.M. Chen. 2013. "UAV LiDAR for below-canopy forest surveys." Review of. Unmanned Vehicle Systems 1 (1):61-8.

Civil Aviation Authority. 2015. Unmanned Aircraft Fact Sheet 1; Consent Rule 101.207(a): for Regional Councils \& Territorial Authorities. Civil Aviation Authority. New Zealand.

Clarke, R., and L. B. Moses. 2014. "The Regulation of Civilian Drones' Impacts on Public Safety." Computer Law \& Security Review 30 (3):263-285. doi: 10.1016/j.clsr.2014.03.007.

Colomina, I., and P. Molina. 2014. "Unmanned Aerial Systems for Photogrammetry and Remote Sensing: A Review." ISPRS Journal of Photogrammetry and Remote Sensing 92:79-97. doi: 10.1016/j.isprsjprs.2014.02.013.

Davy, C., A.T. Ford, A.T. and K.T. Fraser. 2017: Aeroconservation for the Fragmented Skies. Conservation Letters, doi:10.1111/conl.12347.

Dear, E. J., P.-J. Guay, R. W. Robinson, and M. A. Weston. 2015. "Distance from Shore Positively Influences Alert Distance in Three Wetland Bird Species." Wetlands Ecology and Management 23 (2):315-318.

Detweiler, C., J-P. Ore, D. Anthony, S. Elbaum, A. Burgin, and A. Lorenz. 2015.

"Environmental Reviews and Case Studies: Bringing Unmanned Aerial Systems Closer 
to the Environment." Review of. Environmental Practice 17 (3):188-200. doi: $10.1017 / \mathrm{S} 1466046615000174$

Ditmer, M. A., J. B. Vincent, L. K. Werden, J. C. Tanner, T. G. Laske, P. A. Iaizzo, D. L. Garshelis, and J. R. Fieberg. 2015. "Bears Show a Physiological but Limited Behavioral Response to Unmanned Aerial Vehicles." Current Biology 25 (17):2278-2283.

Dulava, S., Bean, W. T., \& Richmond, O. M. W. (2015). Environmental Reviews and Case Studies: Applications of Unmanned Aircraft Systems (UAS) for Waterbird Surveys. Environmental Practice, 17(3), 201-210.

Durban, J. W., Fearnbach, H., Barrett-Lennard, L. G., Perryman, W. L., \& Leroi, D. J. (2015). Photogrammetry of killer whales using a small hexacopter. Journal of Unmanned Vehicle Systems, 3, 131-135.

Dryanovski, I., R. G. Valenti, and J. Xiao. 2013. "An Open-Source Navigation System for Micro Aerial Vehicles." Autonomous Robots 34 (3):177-188. doi: 10.1007/s10514-0129318-8.

Evans, L. J., T. H. Jones, K. Pang, M. N. Evans, S. Saimin, and B. Goossens. 2015. "Use of Drone Technology as a Tool for Behavioral Research: A Case Study of Crocodilian Nesting." Herpetological Conservation and Biology 10 (1):90-98.

Fox, A., and J. Madsen. 1997. "Behavioural and Distributional Effects of Hunting Disturbance on Waterbirds in Europe: Implications for Refuge Design." Journal of Applied Ecology: 1-13.

Freeman, P. K., and R. S. Freeland. 2014. "Politics \& Technology: US Polices Restricting Unmanned Aerial Systems in Agriculture." Food Policy 49:302-311. doi: 10.1016/j.foodpol.2014.09.008. 
Giboney, P. 2015. "Don't Ground Me Bro - Private Ownership of Airspace and How It Invalidates the FAA's Blanket Prohibition on Low Altitude Commercial Drone Operations." Florida Law Review 67.6: 2149-2182.

Gill, J. A. 2007. "Approaches to Measuring the Effects of Human Disturbance on Birds." Ibis 149 (s1):9-14.

Glover, H. K., M. A. Weston, G. S. Maguire, K. K. Miller, and B. A. Christie. 2011. "Towards Ecologically Meaningful and Socially Acceptable Buffers: Response Distances of Shorebirds in Victoria, Australia, to Human Disturbance." Landscape and Urban Planning 103 (3):326-334.

Goebel, M. E., Perryman, W. L., Hinke, J. T., Krause, D. J., Hann, N. A., Gardner, S., \& LeRoi, D. J. (2015). A small unmanned aerial system for estimating abundance and size of Antarctic predators. Polar Biology, 38(5), 619-630.

Gonzalez, L. F., G. A. Montes, E. Puig, S. Johnson, K. Mengersen, and K. J. Gaston. 2016. "Unmanned Aerial Vehicles (UAVs) and Artificial Intelligence Revolutionizing Wildlife Monitoring and Conservation." Sensors 16 (1):97.

Guay, P.-J., W. F. van Dongen, R. W. Robinson, D. T. Blumstein, and M. A. Weston. 2016. "AvianBuffer: An Interactive Tool for Characterising and Managing Wildlife Fear Responses." Ambio: 1-11.

Hahn, N., et al. (2016). "Unmanned aerial vehicles mitigate human-elephant conflict on the borders of Tanzanian Parks: a case study." Oryx 1-4. doi:10.1017/S0030605316000946 Hodgson, A., N. Kelly, and D. Peel. 2013. "Unmanned Aerial Vehicles (UAVs) for Surveying Marine Fauna: A Dugong Case Study." PloS one 8 (11):e79556.

Hodgson, J. C, and L. Koh. 2016. "Best Practice for Minimising Unmanned Aerial Vehicle Disturbance to Wildlife in Biological Field Research." Current Biology 26 (10): R404R405. 
Hoffer, N. V., C. Coopmans, A. M. Jensen, and Y. Chen. 2014. "A Survey and Categorization of Small Low-Cost Unmanned Aerial Vehicle System Identification." Journal of Intelligent \& Robotic Systems 74 (1):129-145. doi: 10.1007/s10846-013-9931-6.

IUCN. 2015. "Red List Table 8: Total Endemic and Threatened Endemic Species in each Country (totals by taxonomic group)." Accessed 29 June. http://cmsdocs.s3.amazonaws.com/summarystats/20154_Summary_Stats_Page_Documents/2015_4_RL_Stats_Table_8.pdf Jasanoff, S. S. 1987. "Contested Boundaries in Policy-Relevant Science." Social Studies of Science 17 (2):195-230.

Jones, G. P., L. G. Pearlstine, and H. F. Percival. 2006. "An Assessment of Small Unmanned Aerial Vehicles for Wildlife Research." Wildlife Society Bulletin 34 (3):750-758. doi: 10.2193/0091-7648(2006)34[750:aaosua]2.0.co;2.

Klemas, V. 2011. "Remote Sensing of Wetlands: Case Studies Comparing Practical Techniques." Journal of Coastal Research 27 (3):418-427. doi: 10.2112/jcoastres-d-1000174.1.

Koh, L. P., \& Wich, S. A. (2012). Dawn of drone ecology: Low-cost autonomous aerial vehicles for conservation. Tropical Conservation Science, 5(2), 121-132.

Lambertucci, S. A., E. L. Shepard, and R. P. Wilson. 2015. "Human-Wildlife Conflicts in a Crowded Airspace.” Science 348 (6234):502-504.

Lehmann, J. R. K., Münchberger, W., Knoth, C., Blodau, C., Nieberding, F., Prinz, T., Pancotto, V. A., \& Kleinebecker, T. (2016). High-Resolution Classification of South Patagonian Peat Bog Microforms Reveals Potential Gaps in Up-Scaled CH4 Fluxes by use of Unmanned Aerial System (UAS) and CIR Imagery. Remote Sensing, 8(3), 173. 
Leon, J. X., C. M. Roelfsema, M. I. Saunders, and S. R. Phinn. 2015. "Measuring coral reef terrain roughness using 'Structure-from-Motion' close-range photogrammetry." Review of. Geomorphology 242:21-8. doi: 10.1016/j.geomorph.2015.01.030.

Liley, D., and W. J. Sutherland. 2007. "Predicting the Population Consequences of Human Disturbance for Ringed Plovers Charadrius hiaticula: A Game Theory Approach." Ibis 149:82-94. doi: 10.1111/j.1474-919X.2007.00664.x.

Limnaios, G., and N. Tsourveloudis. 2012. "Introduction." In Sense and Avoid in UAS: Research and Applications, edited by P.J. Delves and P.P. Angelov. Hoboken, NJ, USA: John Wiley and Sons.

Linchant, J., J. Lisein, J. Semeki, P. Lejeune, and C. Vermeulen. 2015. "Are Unmanned Aircraft Systems (UASS) The Future of Wildlife Monitoring? A Review of Accomplishments and Challenges." Mammal Review 45 (4):239-252. doi: 10.1111/mam.12046.

Lord, A., J. R. Waas, J. Innes, and M. J. Whittingham. 2001. "Effects of Human Approaches to Nests of Northern New Zealand Dotterels." Biological Conservation 98 (2):233-240.

Lucieer, A., S. M. de Jong, and D. Turner. 2014. "Mapping landslide displacements using Structure from Motion (SfM) and image correlation of multi-temporal UAV photography." Review of. Progress in Physical Geography 38 (issue 1):97-116. doi: $10.1177 / 0309133313515293$

MarketLine. 2014. Unmanned Aerial Vehicles - The Economic Case for Drones. S.1.: MarketLine, a Datamonitor business.

Mawdsley, J. R., R. O’Malley, and D. S. Ojima. 2009. "A Review of Climate-Change Adaptation Strategies for Wildlife Management and Biodiversity Conservation." Conservation Biology 23 (5):1080-1089. 
McEvoy, J.F., G.P. Hall, and P. G. McDonald. 2016 "Evaluation of Unmanned Aerial Vehicle Shape, Flight Path and Camera Type for Waterfowl Surveys: Disturbance Effects and Species Recognition." PeerJ 4: e1831.

Meier, L., P. Tanskanen, L. Heng, G. H. Lee, F. Fraundorfer, and M. Pollefeys. 2012. "PIXHAWK: A Micro Aerial Vehicle Design for Autonomous Flight Using Onboard Computer Vision." Autonomous Robots 33 (1-2):21-39. doi: 10.1007/s10514-0129281-4

Merino, L., F. Caballero, J. R. Martínez-de-Dios, I. Maza, and A. Ollero. 2012. "An Unmanned Aircraft System for Automatic Forest Fire Monitoring and Measurement." Journal of Intelligent \& Robotic Systems 65 (1-4):533-548.

Ministry for the Environment. 2007. Protecting our Places: Information about the Statement of National Priorities for Protecting Rare and Threatened Native Biodiversity on Private Land. Wellington, New Zealand: Ministry for the Environment.

Møller, A. P., D. S. Samia, M. A. Weston, P.-J. Guay, and D. T. Blumstein. 2014. "American Exceptionalism: Population Trends and Flight Initiation Distances in Birds from Three Continents." PloS one 9 (9):e107883.

Mulero-Pázmány, M., Stolper, R., Essen, L. D. v., Negro, J. J., \& Sassen, T. (2014). Remotely Piloted Aircraft Systems as a Rhinoceros Anti-Poaching Tool in Africa: e83873. PLoS One U6.

Navedo, J. G., and A. G. Herrera. 2012. "Effects of Recreational Disturbance on Tidal Wetlands: Supporting the Importance of Undisturbed Roosting Sites for Waterbird Conservation." Journal of Coastal Conservation 16 (3):373-381.

Nishar, A., S. Richards, D. Breen, J. Robertson, and B. Breen. 2016. "Thermal infrared imaging of geothermal environments and by an unmanned aerial vehicle (UAV): A case study of 
the Wairakei - Tauhara geothermal field, Taupo, New Zealand." Review of. Renewable Energy 86:1256-64. doi: http://dx.doi.org/10.1016/j.renene.2015.09.042.

Peasgood, S., and M.Valentin. (2015). Drones: a Rising Market. Retrieved from http://sophiccapital.com/wp-content/uploads/2015/09/Download-Sophic-CapitalsAerial-Drone-Report-Here.pdf.

Ramsey, C. L., P. A. Griffiths, and T. R. Stokes. 2014. "Multi-rotor unmanned aerial vehicles (UAVs) and high-resolution compact digital cameras: a promising new method for monitoring changes to surface karst resources." Review of. Acta Cartologica 43 $(2 / 3): 269$

Rodríguez, A., Negro, J. J., Mulero, M., Rodríguez, C., Hernández-Pliego, J., \& Bustamante, J. (2012). The Eye in the Sky: Combined Use of Unmanned Aerial Systems and GPS Data Loggers for Ecological Research and Conservation of Small Birds: e50336. PLoS One, $7(12), 1-8$

Rümmler, M.-C., O. Mustafa, J. Maercker, H.-U. Peter, and J. Esefeld. 2015. "Measuring The Influence of Unmanned Aerial Vehicles on Adélie Penguins." Polar Biology:1-6.

Sandvik, K. B., and K. Lohne. 2014. "The Rise of the Humanitarian Drone: Giving Content to an Emerging Concept." Millennium - Journal of International Studies 43 (1):145-164.

Scherer, S., J. Rehder, S. Achar, H.Cover, A.Chambers, S.Nuske, and S.Singh. 2012. "River Mapping from a Flying Robot: State Estimation, River Detection, and Obstacle Mapping." Autonomous Robots 33 (1-2):189-214.

Scobie, C.A., and C.H. Hugenholtz. "Wildlife Monitoring with Unmanned Aerial Vehicles: Quantifying Distance to Auditory Detection." Wildlife Society Bulletin (2016).

Siebert, S., and J. Teizer. 2014. "Mobile 3D mapping for surveying earthwork projects using an Unmanned Aerial Vehicle (UAV) system." Review of. Automation in Construction 41:1-14. doi: 10.1016/j.autcon.2014.01.004. 
Springer, P. J. 2013. Military Robots and Drones: A Reference Handbook. Santa Barbara, CA, USA: ABC-CLIO.

Stanley, M. C., J. R. Beggs, I. E. Bassett, B. R. Burns, K. N. Dirks, D. N. Jones, W. L. Linklater, C. Macinnis-Ng, R. Simcock, and G. Souter-Brown. 2015. "Emerging Threats in Urban Ecosystems: A Horizon Scanning Exercise." Frontiers in Ecology and the Environment 13 (10):553-560.

Tarr, N. M., T. R. Simons, and K. H. Pollock. 2010. "An Experimental Assessment of Vehicle Disturbance Effects on Migratory Shorebirds." The Journal of Wildlife Management 74 (8):1776-1783.

Thompson, S., and A. Saulnier. 2015. "The "Rise" of Unmanned Aerial Vehicles (UAVs) in Canada: An Analysis of Special Flight Operation Certificates (SFOCs) from 2007 to 2012." Canadian Public Policy-Analyse De Politiques 41 (3):207-222. doi:

Formatted: French (France) 10.3138/cpp.2014-038.

Tirian, O. G. 2014. "Drone for Military Applications." Annals of the Faculty of Engineering Hunedoara 12 (4):239.

Van der Zande, A., and T. Verstrael. 1985. "Impacts of Outdoor Recreation upon Nest-Site Choice and Breeding Success of the Kestrel." Ardea 73:90-99.

Vas, E., A. Lescroël, O. Duriez, G. Boguszewski, and D. Grémillet. 2015. "Approaching Birds with Drones: First Experiments and Ethical Guidelines." Biology letters 11 (2):20140754

Vasuki, Y., E-J. Holden, P. Kovesi, and S. Micklethwaite. 2014. "Semi-automatic mapping of geological Structures using UAV-based photogrammetric data: An image analysis approach." Review of. Computers \& Geosciences 69:22-32. doi: 10.1016/j.cageo.2014.04.012. 
Wallace, P. 2016. "Managing Human Disturbance of Wildlife in Coastal Areas." New Zealand Geographer.

Watts, A. C., V. G. Ambrosia, and E. A. Hinckley. 2012. "Unmanned Aircraft Systems in Remote Sensing and Scientific Research: Classification and Considerations of Use." Remote Sensing 4 (6):1671-1692. doi: 10.3390/rs4061671.

Weissensteiner, M. H., J. W. Poelstra, and J. B. W. Wolf. 2015. "Low-Budget Ready-to-Fly Unmanned Aerial Vehicles: An Effective Tool for Evaluating the Nesting Status of Canopy-Breeding Bird Species." Journal of Avian Biology 46 (4):425-430. doi: 10.1111/jav.00619.

Weston, M. A., E. M. McLeod, D. T. Blumstein, and P.-J. Guay. 2012. "A Review of FlightInitiation Distances and their Application to Managing Disturbance to Australian Birds." Emu:269-286.

Weston, M. A., T. A. Schlacher, and D. Lynn. 2014. "Pro-Environmental Beach Driving is Uncommon and Ineffective in Reducing Disturbance to Beach-Dwelling Birds.” Environmental Management 53 (5):999-1004.

Whitehead, K., Hugenholtz, C. H., Myshak, S., Brown, O., LeClair, A., Tamminga, A., Barchyn, T. E., Moorman, B., \& Eaton, B. (2014). Remote Sensing of the Environment with Small Unmanned Aircraft Systems (UASs), part 2: Scientific and Commercial Applications. Journal of Unmanned Vehicle Systems, 2(3), 86-102.

Wing, M. G., J. Burnett, J. Sessions, J. Brungardt, V. Cordell, D. Dobler, and D. Wilson. 2013. "Eyes in the sky: Remote sensing technology development using small unmanned aircraft systems." Review of. Journal of Forestry 111 (5):341-7. doi: 10.5849/jof.12117.

Woodley, K. Shorebirds of New Zealand; Sharing the Margins. New Zealand: Penguin Books (NZ) Ltd, 2012. 
Zolderdo, A. J., D. P. Struthers, S. J. Cooke, H. L. J. Stemberger, and M. J. Lawrence. 2015.

"The Effects of Modern War and Military Activities on Biodiversity and the

Environment." Environmental Reviews 23 (4):443-460. doi: 10.1139/er-2015-0039.

Zuberogoitia, I., J. Zabala, J. Martínez, J. González-Oreja, and P. López-López. 2014.

"Effective Conservation Measures to Mitigate the Impact of Human Disturbances on the Endangered Egyptian Vulture." Animal Conservation 17 (5):410-418. 